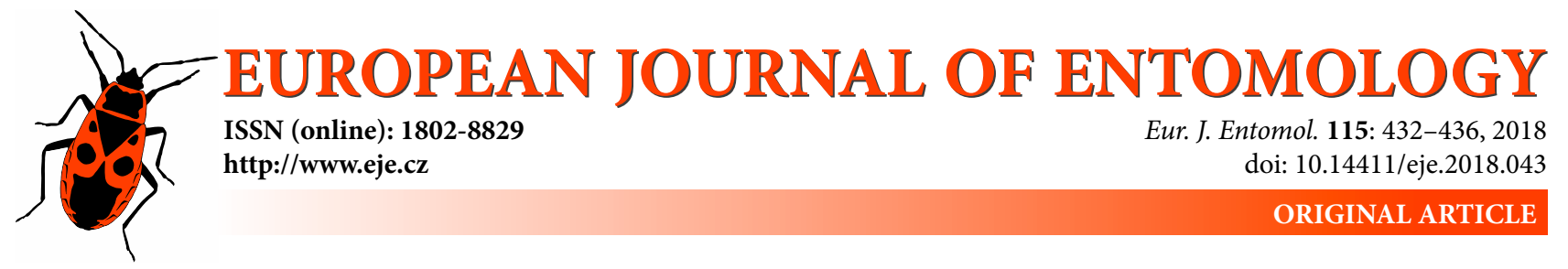

\title{
Daily survival and dispersal of adult Rhagonycha fulva (Coleoptera: Cantharidae) in a wooded agricultural landscape
}

\author{
Laura E. RODWELL, Jennifer J. DAY, Christopher W. FOSTER and Graham J. HOLLOWAY
}

Centre for Wildlife Assessment and Conservation, School of Biological Sciences, Harborne Building, The University of Reading, Reading RG6 2AS, UK; e-mails: Laurarodwell21@hotmail.co.uk, jennday1@live.com, c.w.foster@reading.ac.uk, g.j.holloway@reading.ac.uk

Key words. Coleoptera, Cantharidae, Rhagonycha fulva, Hogweed bonking beetle, soldier beetle, mark re-sighting, movement, settling, longevity, landscape connectivity, landscape configuration

\begin{abstract}
Studies of insect population under field conditions to establish survival rates, longevity and dispersal rates are rare in the literature. These types of studies are important and can be used to inform studies of the effects of landscape composition and configuration on levels of biodiversity. Here the Cantharidae beetle, Rhagonycha fulva is studied under field conditions to derive estimates of daily survival rates for both males and females as well as local dispersal rates. Survival was studied at two sites, one in Wales and another in England, whilst dispersal was examined only at the Welsh site. Beetles were marked using different coloured enamel paints at the mid-point of a $200 \mathrm{~m}$ linear transect. The beetles were almost exclusively found (and marked) on common hogweed, Heracleum sphondylium. No difference in survival was found between males and females at both of the sites. The survival rates found at the two sites also did not differ. The overall daily survival rate was 0.771 equating with a median longevity of 4.37 days. Casual observations yielded a small number of marked individuals in excess of $400 \mathrm{~m}$ away from the point of marking. Movement of males along the transect differed from females. Marked females were never found far from the point of marking whilst males moved further away with time. This difference in behaviour is discussed in terms of hypothesized insect dispersal behaviour following emergence as mobile adults.
\end{abstract}

\section{INTRODUCTION}

Dispersal is a fundamental component of an insect's life history. Dispersal describes an organism's movement in space (Benton \& Bowler, 2012; Travis et al., 2012) which maintains gene flow across a population (Saastamoinen et al., 2018), avoids inbreeding and supports genetic diversity (Kautz et al., 2016; Baines et al., 2017). Genetic diversity has been recognised as a factor required for life history plasticity when faced with environmental change (Holloway et al., 1990; Callaghan \& Holloway 1999; Ottenheim et al., 1999; Kautz et al., 2016). Thus, dispersal behaviour is highly influential in preventing population extinction (Clobert, 2012; Saastamoinen et al., 2018). Plasticity might be important in altered or changing landscapes. Agricultural activity, industrialisation and urbanisation have resulted in habitat fragmentation and destruction resulting in smaller and more isolated remnants left for those species affected (Didham, 2010; Rossetti et al., 2017). The ability of a species to transverse between patches, to find suitable mates and to mix genetic material across the population is key to survival in many species of insects (Vanden Broeck et al., 2017).
Some studies suggest that gender is related to dispersal proclivity (Bowler \& Benton, 2009; De Meester \& Bonte, 2010; Baines et al., 2017). This is particularly the case when an individual's dispersal behaviour is predominantly driven by local, intra-sexual competition for resources such as food, space and mating opportunities (Baines et al., 2017). Consequently it has been argued that unless dispersal models account for sex related dispersal, findings cannot be broadly applied (Miller et al., 2011). Few dispersal studies incorporate sex-bias, but those that do generally conclude evidence of male-biased dispersal (Miller et al., 2011; Dobson, 2013; Baines et al., 2017). However, Holloway et al. (2003) investigated the sex-biased dispersal of hornet robber flies (Asilus crabroniformis L.), and found no difference between male and female dispersal distances.

Biodiversity is strongly impacted by dispersal ability (Diekötter et al., 2008). A matrix of landscape elements is referred to as landscape heterogeneity and is influential in encouraging biodiversity within an anthropogenically altered landscape (Neumann et al., 2015, 2016). Neumann et al. (2015) described the vitality of 'countryside elements', such as hedgerows and field margins, for providing connectivity between habitats, facilitating species movement 
(Haslem \& Bennett, 2008). Conducting studies on insect dispersal within a semi-natural and linear habitat, specifically a field margin, provides an insight to the quality of the field margins (Diekötter et al., 2008) and could also function as an indicator for how other species may move within that habitat type (Della Rocca et al., 2017).

Mark-recapture, or re-sight, techniques have been utilized in multiple insect dispersal studies. Taxonomic groups that have been considered include Syrphidae (Holloway \& McCaffery, 1990; Rotheray et al., 2014), Asilidae (Holloway et al., 2003), Acrididae (Narisu et al., 1999), Zygoptera (Keller \& Holderegger, 2013) and Scarabaeidae (Cultid-Medina et al., 2015). A variety of marking techniques has been deployed and includes marker pens (Daily et al., 1991), fluorescent powders (Narisu et al., 1999; Cronin et al., 2008) and reflective tags (Diekötter et al., 2005; Walters et al., 2006). Holloway \& McCaffery (1990) and Holloway et al. (2003) used an in situ (in the field) approach for marking and monitoring the dispersal of hoverflies (Eristalis pertinax Scopoli) and hornet robber flies (A. crabroniformis), respectively, using enamel paint to mark individuals. It has been argued that in situ marking is preferable to laboratory rearing, marking and subsequent release (Downey et al., 2015).

The focal species of this study, Rhagonycha fulva (Scopoli) (Coleoptera: Cantharidae), is abundant across the British Isles (Chinery, 1993; Gibbons, 2014). After undergoing complete metamorphosis, $R$. fulva emerge as adults towards the end of June to copulate and oviposit, before the end of the flight season in early August (Chinery, 1993). In Britain, they are predominately found upon canopy flowers of the Apiaceae, such as common hogweed (Heracleum sphondylium L.), feeding on pollen, nectar and predating small insects (Gibbons, 2014). Rhagonycha fulva individuals are 10-15 mm long and their movement depends primarily on food and mate availability (e.g. McLain et al., 2015; Pratt et al., 2017). Major gaps in the literature on $R$. fulva include estimates of their daily survival rate and average longevity.

The aims of the present study were to provide new information on $R$. fulva life-history, specifically sex-related daily survival rate, median longevity and dispersal capacity.

\section{METHODS}

\section{Study sites}

Data were collected from two locations: one in southern Wales (grid reference: ST180694) and the second in southern England (grid reference: TL 086058). In Wales data were collected between July $1^{\text {st }}$ and August $10^{\text {th }} 2017$ whilst from England data were collected slightly later in the year (from July $5^{\text {th }}$ ). The Welsh data were used to estimate daily survival and dispersal rates during the period of peak activity of $R$. fulva. The English study was carried out to establish whether survival rates remained similar towards the end of the R. fulva season but did not contribute to the dispersal distance since hogweed was beginning to die back during the study.

Each study site consisted of a $210 \mathrm{~m}$ long $2 \mathrm{~m}$ deep linear transect along a field margin in lowland, wooded, agricultural landscape. Linear habitats are known to facilitate insect movement (Neumann et al., 2016). Both transects were dominated by Apiaceae, in particular hogweed (H. sphondylium). Rhagonycha fulva associates very closely with hogweed in Britain, hence its vernacular name hogweed bonking beetle. Transects were split into $10 \mathrm{~m}$ sections and the central section was designated as the region in which beetles were to be marked.

\section{Data collection}

Marking was carried out using different coloured enamel paints using the method devised by Holloway \& McCaffery (1990). Enamel paint was found to be a highly effective material for marking and further made individual subjects recognisable by using different colours. A preliminary study was carried out in June 2017 towards the beginning of the R. fulva season to investigate the effectiveness of using enamel paints, which part of the body to target for marking and the best time of the day to mark. Paint was applied using a sharp, wooden cocktail stick. A different coloured paint was used each day and marking was continued for 14 consecutive days. Beetles were marked on the pronotum being careful to avoid touching the elytra to avoid sticking the elytra together and hence preventing flight. Insects were marked whilst feeding on hogweed and did not take evasive action or fly away following marking. To facilitate collection of sex-related data, insects were marked whilst in copula whenever possible. Males were marked on the left side of the pronotum and females on the right side of the pronotum. Single insects were also marked and sex was determined based on morphological characteristics (males are slimmer than females and the pygidium extends beyond the tip of the elytra).

Marking insects at the Welsh site started on the $1^{\text {st }}$ July and re-sightings were made daily from the $2^{\text {nd }}$ July between 14.00 and 16.00 BST terminating on the $10^{\text {th }}$ August when no marked beetles had been seen for a period of five days. At the English site the corresponding start and finish dates were $5^{\text {th }}$ July and $3^{\text {rd }}$ August. The marking colour of the beetles re-sighted provided information on longevity whilst the $10 \mathrm{~m}$ section in which they were re-sighted provided information on distance travelled. The transects were walked along in a random manner assessing either the left or the right side first starting at the distal or the proximal end (relative to the central section)

Statistical analyses were carried out using Minitab version 18. Survival values plotted against time produces negative exponential curve. Log transformation produces a straight line facilitating analysis (Holloway \& McCaffery, 1990). Linear regression was carried out on plots of $\log _{10}$ percentage re-sighted on $\log _{10}$ day. Back transformation was applied to estimate daily survival rate (p) using

$$
p=\operatorname{antilog}\left(\frac{b}{10}\right)
$$

where $b=$ regression coefficient.

Survival rates were compared using analysis of variance. Median longevity (L) in days (Nielsen, 1969) was calculated using:

$$
L=\frac{1}{1-p}
$$

Distance moved along transects by male and female insects were compared using t-tests.

\section{RESULTS}

A total of 1187 beetles were marked, 582 in Wales (352 males and 230 females) and 605 in England (287 males and 318 females). Fig. 1 shows the percentage of individuals 


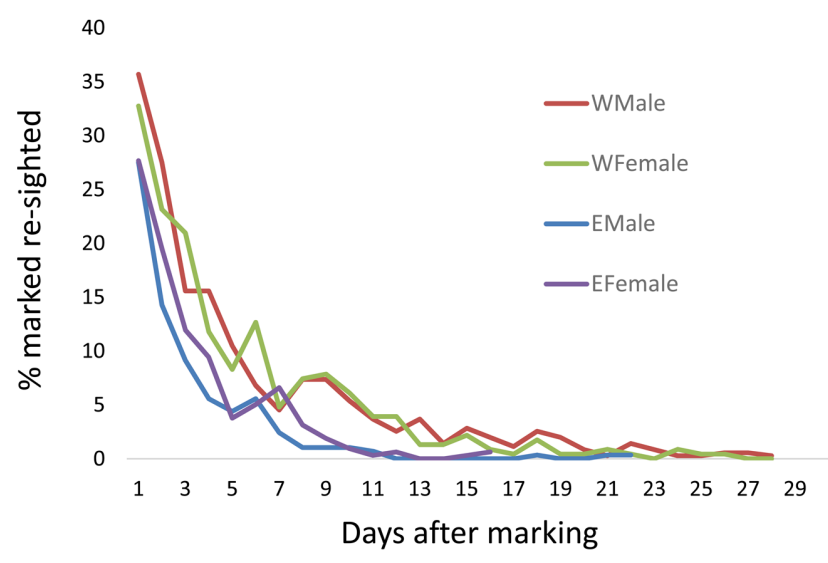

Fig. 1. Mean percentage of male and female Rhagonycha fulva re-sighted each day after marking at the Welsh (W) and English (E) study sites.

re-sighted for each day after marking. The maximum male longevity was 28 days and for females was 26 days (Welsh study). A plot of $\log _{10}$ proportion on $\log _{10}$ day generated a straight line facilitating estimation of daily survival rates (Fig. 2) assuming that the large drop in re-sightings on the first day after marking represented emigration from the site (Holloway \& McCaffery, 1990). For the Welsh population, daily survival rates were $0.776 \pm 0.042$ for males and 0.768 \pm 0.052 for females. There was no significant difference between the survival rates for males and females $\left[\mathrm{F}_{1,52}=\right.$ 0.94 , ns (not significant)]. The median adult longevity was estimated as 4.5 days for males and 4.3 days for females. For the English population, daily survival rates were 0.760 \pm 0.042 for males and $0.742 \pm 0.052$ for females. There was no significant difference between the survival rates for males and females $\left(\mathrm{F}_{1,41}=1.85\right.$, ns). The median longevity was 4.17 days for males and 3.88 days for females.

There was no significant difference between male survival rate from the Welsh population and the male survival rate from the English population $\left(\mathrm{F}_{1.46}=0.91, \mathrm{~ns}\right)$ so the males data sets were combined (combined survival rate $=$ $0.781 \pm 0.06$ ). There was no significant difference between the female data sets from the two sites $\left(\mathrm{F}_{1,46}=0.8, \mathrm{~ns}\right)$ so the female data sets were combined (combined survival rate $=0.76 \pm 0.05$ ). There was no significant difference between male and female survival rates overall $\left(\mathrm{F}_{1,96}=1.07\right.$,

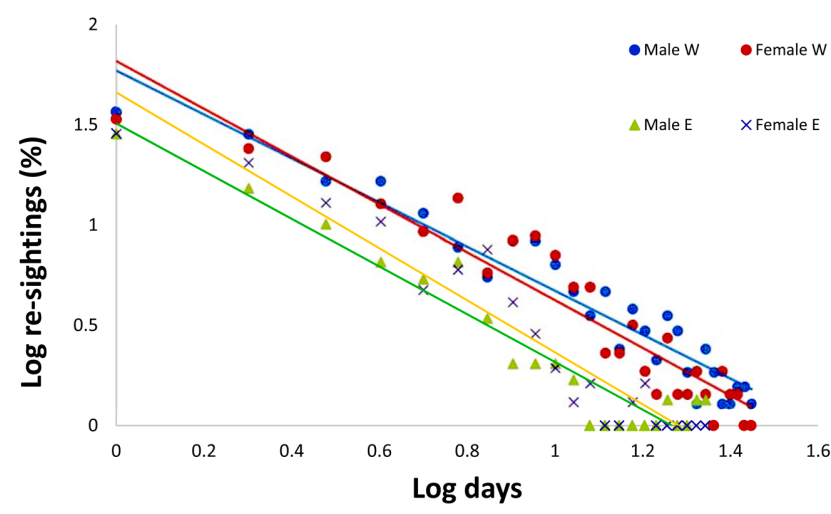

Fig. 2. $\log _{10}$ proportion Rhagonycha fulva re-sighted on $\log _{10}$ days after marking at the Welsh and English study sites.

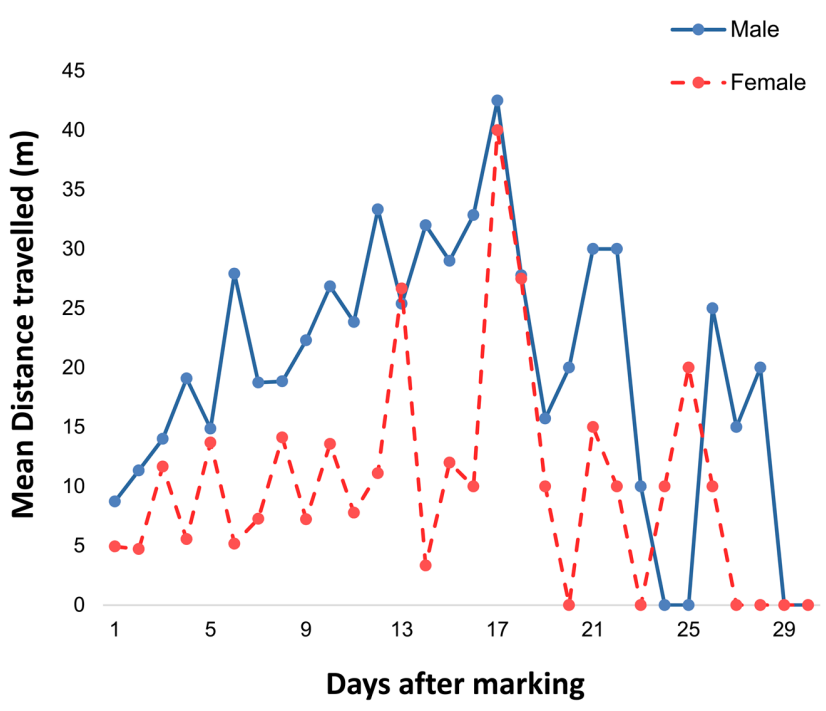

Fig. 3. Mean distance travelled by male and female Rhagonycha fulva on days after marking at the Welsh study site.

ns) and the combined survival rate was $0.771 \pm 0.038$. The combined median longevity was 4.37 days (males $=4.57$; females $=4.17$ ).

Fig. 3 shows the mean distance travelled by individual R. fulva on days after marking (i.e. age) for the Welsh site. Females were not usually recorded far from the marking zone in the middle of the transect. The mean value on each day tended to lie between $10 \mathrm{~m}$ and $15 \mathrm{~m}$ from the point of marking. Male moved progressively further from the point of marking as they aged up to a mean of $43 \mathrm{~m}$ from the marking zone on 17 days after marking. From 18 days onwards after marking the mean male distance from the point of marking declined. A paired t-test indicated that the male and female mean dispersal distance differed with age $\left(t_{27}=5.15, p<0.01\right)$. Casual observations (i.e. not part of the experimental design) produced sightings of three male individuals over $400 \mathrm{~m}$ from the study site (English study).

\section{DISCUSSION}

Rhagonycha fulva is an extremely common species in Britain. Despite this very little is known about its life history and behaviour under field conditions. The study presented here is the first mark re-sighting study carried out on the species as far as we know. The daily survival rate was not found to differ significantly between sexes nor between the two study sites. The combined daily survival rate was 0.771 . There are very few similar estimates of insect survival under field conditions with which to compare the value of daily survival found here. One exception is the work of Holloway \& McCaffery (1990) who worked on Eristalis pertinax. The estimate of mean male survival rate was 0.763 and they also found that survival rate was not sex-related.

It is reasonable to assume that for many species the greater the longevity the greater the capacity to disperse and perhaps the greater resilience a species displays to landscape change (Bubová et al., 2016). There are many studies on the effects of landscape composition and config- 
uration on levels of biodiversity (Della Rocca et al., 2017). Inherent in these studies is that those species with a more limited power of dispersal are more likely to be affected by landscape features, particularly at a local level. For example, Neumann et al. (2015) working on ground beetles found an effect of landscape configuration on ground beetle communities, in particular large flightless species were more affected. In a similar study Neumann et al. (2016) found no effect of landscape configuration on bird diversity. The feature connecting these studies and influencing the outcome of the results is the power of dispersal. In very mobile species, such as birds and flighted ground beetles, there was no effect of landscape configuration. In flightless species and those with more limited powers of dispersal there was an effect. One possible consequence of limited dispersal is that insect populations could have a substantial probability of extinction but offer with very limited probability of recolonizing vacant habitats (Neumann et al., 2017). The current study demonstrates that $R$. fulva can live for over 25 days and is able to move at least $400 \mathrm{~m}$. It is possible that they have the capacity to disperse for a considerable distance across the landscape. Furthermore, the data reported here were collected in situ and are therefore relevant to studies on the effects of landscape on biodiversity. Whilst studies on longevity carried out ex situ can be more straight-forward it has been found that laboratory derived estimates of longevity do not correlate well with field estimates on the same species (Faccoli et al., 2015)

In the current study, it was assumed that the large drop in re-sightings on the first day was caused by individual emigrating from the study site, i.e. engaging with wider dispersal. Holloway \& McCaffery (1990) noted a similar phenomenon. Working with a hoverfly, E. pertinax, they noted that the freshly emerged individuals with teneral wings that were marked were unlikely to be seen again. To explain this Holloway \& McCaffery (1990) argued that $E$. pertinax dispersed shortly after emergence from pupa and that the observation did not reflect a very high mortality during the first day of adult life. During the current study there was little evidence of mortality. Throughout the entire study only five marked beetles were observed being actively predated by spiders. It is possible that, as with $E$. pertinax, newly emerged adults were more likely than older individual to actively disperse across the countryside.

Casual observations indicated that individuals can move $400 \mathrm{~m}$ across the landscape. It is possible that some individuals moves further but the greater the distance moved from the study site the smaller the chance that they will be discovered. The data from the Welsh site showed local movement (within transect) of males differed significantly from females. There are many reasons why the behaviours of the two sexes might differ locally. Holloway \& McCaffery (1990) found females congregating close to potential breeding sites whilst males were more likely to be found in the open on flowers. Holloway et al. (2003) working on the hornet robber fly, A. crabroniformis L. found that males were less likely to be recovered from breeding sites than females. Very little is known about the breed- ing behaviour of $R$. fulva so it is possible that similar sexrelated activity occurred in the current study.

Travis et al. (2012) and Kautz et al. (2016) describe dispersal in insects as a process consisting of three key stages: (1) emigration, (2) movement and (3) settlement. Again, there are no data on any aspect of the dispersal process in R. fulva but it is likely that the first two phases occur in younger adult beetles. Young beetles probably disperse soon after emergence and leave the immediate site of emergence. On landing following dispersal, movement might occur to locate a good breeding or feeding site. Having found an acceptable site an individual might settle to feed and breed. Fig. 3 indicates that the two sexes did behave differently on the Welsh study site. It is not necessarily the case that males and females behave exactly the same when it comes to the three stages of dispersal. They might disperse at slightly different ages or move different distances. Likewise their movement activities could differ resulting in settlement at different ages. It is possible that the only beetles re-sighted during the study were engaged in either (local) movement or settlement. If most of the females had settled it would explain why there was little evidence of movement away from the point of marking. If males principle activity is to find mates there might be less incentive to disperse if dispersing females are settling close to male emergence sites and offering mating opportunities. This could result in males dispersing or moving at an older age than females. If this happened it could account for the steady increase in mean distance from the point of marking (Fig. 3) as males move until 17 days old with a net emigration from day 18 onwards leaving only males that had settled anyway.

With the number of studies on effects of landscape on biodiversity currently appearing in scientific literature it is more important than ever to have data on what insect species are doing in the wider landscape.

ACKNOWLEDGEMENTS. We would like to thank the staff at Cosmeston Country Park for accommodating and supporting the field work for this study. We are very grateful to two anonymous referees for their constructive comments on a earlier draft.

\section{REFERENCES}

Baines C.B., Ferzoco I.M. \& McCauley S.J. 2017: Sex-biased dispersal is independent of sex ratio in a semiaquatic insect. Behav. Ecol. Sociobiol. 71(8): 119, 7 pp.

Benton T.G. \& Bowler D.E. 2012: Dispersal in invertebrates: influences on individual decisions. In Clobert J., Baguette M., Benton T.G. \& Bullock J.M. (eds): Dispersal Ecology and Evolution. Oxford University Press, Oxford, pp. 41-49.

Bowler D.E. \& Benton T.G. 2009: Variation in dispersal mortality and dispersal propensity among individuals: the effects of age, sex and resource availability. - J. Anim. Ecol. 78: 1234-1241.

Bubová T., Kulma M., Vrabec V. \& Nowicki P. 2016: Adult longevity and its relationship with conservation status in European butterflies. - J. Insect Conserv. 20: 1021-1032.

Callaghan A. \& Holloway G.J. 1990: The relationship between environmental stress and variance. - Ecol. Appl. 9: 456-462.

ChINERY M. 1993: Insects of Britain and Northern Europe - Collins Field Guide. 3rd ed. HarperCollins, London, 320 pp. 
Clobert J. (ED.) 2012: Dispersal Ecology and Evolution. Oxford University Press, Oxford, 496 pp.

Cronin J.T., Hyland K. \& Abrahamson W.G. 2008: The pattern, rate, and range of within-patch movement of a stem-galling fly. - Ecol. Entomol. 26: 16-24.

Cultid-Medina C.A., Martínez-Quintero B.G., Escobar F. \& de UlloA P.C. 2015: Movement and population size of two dung beetle species in an Andean agricultural landscape dominated by sun-grown coffee. - J. Insect Conserv. 19: 617-626.

Daily G.C., Ehrlich P.R. \& Wheye D. 1991: Determinants of spatial distribution of the sub-alpine butterfly Oeneis chryxus. — Oecologia 88: 587-596.

Della Rocca F., Bogliani G. \& Milanesi P. 2017: Patterns of distribution and landscape connectivity of the stag beetle in a human-dominated landscape. - Nature Conserv. 19: 19-37.

De Meester N. \& Bonte D. 2010: Information use and densitydependent emigration in an agrobiont spider. - Behav. Ecol. 21: 992-998.

DiDHAM R.K. 2010: Ecological consequences of habitat fragmentation. - eLS: A21904, 39 pp.

Diekötter T., Csencsics D., Rothenbühler C., Billeter R. \& EDWARDS P.J. 2005: Movement and dispersal patterns in the bush cricket Pholidoptera griseoaptera: the role of developmental stage and sex. - Ecol. Entomol. 30: 419-427.

Diekötter T., Billeter R. \& CRist T.O. 2008: Effects of landscape connectivity on the spatial distribution of insect diversity in agricultural mosaic landscapes. - Basic Appl. Ecol. 9: 298-307.

Dobson F.S. 2013: The enduring question of sex-biased dispersal: Paul J. Greenwood's (1980) seminal contribution. - Anim. Behav. 85: 299-304.

Downey M.H., Searle R., Bellur S., Geiger A., Maitner B.S., OHм J.R., Tuda M. \& Miller T.E. 2015: A comparative approach to testing hypotheses for the evolution of sex-biased dispersal in bean beetles. - Ecol. Evol. 5: 4819-4828.

Faccoli M., Favaro R., Smith M.T. \& Wu J. 2015: Life history of the Asian longhorn beetle Anoplophora glabripennis (Coleoptera, Cermabycidae) in southern Europe. - Agric. Forest Entomol. 17: 188-196.

GibBons B. 2014: Pocket Guide to Insects. 1st ed. Bloomsbury, London, pp. 163-164.

Haslem A. \& Bennett A.F. 2008: Birds in agricultural mosaics: the influence of landscape pattern and countryside heterogeneity. - Ecol. Appl. 18: 185-196.

Holloway G.J. \& McCAFfery A.R. 1990: Habitat utilization and dispersion in Eristalis pertinax (Diptera: Syrphidae). — Entomologist 109: 116-124.

Holloway G.J., Sibly R.M. \& Povey S.R. 1990: Evolution in toxin-stressed environments. - Funct. Ecol. 4: 289-294.

Holloway G.J., Dickson J.D., Harris P.W. \& SMith J. 2003; Dynamics and foraging behaviour of adult hornet robberflies, Asilus crabroniformis: implications for conservation management. - J. Insect Conserv. 7: 127-135.

Kautz M., Imron M.A., Dworschak K. \& Schopf R. 2016: Dispersal variability and associated population-level consequences in tree-killing bark beetles. - Movement Ecol. 4: 9, 12 pp.

Keller D. \& Holderegger R. 2013: Damselflies use different movement strategies for short- and long-distance dispersal. Insect Conserv. Divers. 6: 590-597.

McLain D.K., Pratt A.E. \& Shure D.J. 2015: Size dependence of courtship effort may promote male choice and strong as- sortative mating in soldier beetles. - Behav. Ecol. Sociobiol. 69: $883-894$.

Miller T.E., Shaw A.K., Inouye B.D. \& Neubert M.G. 2011: Sex-biased dispersal and the speed of two-sex invasions. Am. Nat. 177: 549-561.

NARISU, LocKwood J.A. \& Schell S.P. 1999: A novel mark-recapture technique and its application to monitoring the direction and distance of local movements of rangeland grasshoppers (Orthoptera: Acrididae) in the context of pest management. J. Appl. Ecol. 36: 604-617.

Neumann J.L., Griffiths G.H., Hoodless A. \& Holloway G.J. 2015: The compositional and configurational heterogeneity of matrix habitats shape woodland carabid communities in wooded-agricultural landscapes. - Landsc. Ecol. 31: 301-315.

Neumann J.L., Griffiths G.H., Foster C.W. \& Holloway G.J. 2016: The heterogeneity of wooded-agricultural landscape mosaics influences woodland bird community assemblages. Landsc. Ecol. 31: 1833-1848.

Neumann J.L., Holloway G.J., Hoodless A. \& Griffiths G.H. 2017: The legacy of 20th Century landscape change on today's woodland carabid communities. - Divers. Dist. 23: $1447-$ 1458.

NIELSEN T. 1969: Population studies on Helophilus hybridus Loew and Sericomyia silentis (Harris) (Dipt., Syrphidae). Norsk Entomol. Tidsskr. 16: 33-39.

Ottenheim M.M., Wertheim B., Holloway G.J. \& Brakefield P.M. 1999: Survival of colour-polymorphic Eristalis arbustorum hoverflies in semi-field conditions. - Funct. Ecol. 13: $72-77$.

Pratt A.E., Shure D.J., McLain D.K. \& Banderet K. 2017: Male and female soldier beetles relax choice for mate quality across daily courtship periods. - Ethology 123: 175-187.

Rossetti M.R., Tscharntke T., Aguilar R. \& Batáry P. 2017: Responses of insect herbivores and herbivory to habitat fragmentation: a hierarchical meta-analysis. - Ecol. Lett. 20: 264-272.

Rotheray E.L., Bussiere L.F., Moore P., Bergstrom L. \& GoulSON D. 2014: Mark recapture estimates of dispersal ability and observations on the territorial behaviour of the rare hoverfly, Hammerschmidtia ferruginea (Diptera, Syrphidae). - J. Insect Conserv. 18: 179-188.

Saastamoinen M., Bocedi G., Cote J., Legrand D., Guillaume F., Wheat C.W., Fronhofer E.A., Garcia C., Henry R., Husby A. \& Baguette M. 2018: Genetics of dispersal. - Biol. Rev. 93: 574-599.

Travis J.M., Mustin K., Barton K.A., Benton T.G., Clobert J., Delgado M.M., Dytham C., Hovestadt T., Palmer S.C., van Dyck H. \& Bonte D. 2012: Modelling dispersal: an ecoevolutionary framework incorporating emigration, movement, settlement behaviour and the multiple costs involved. - Meth. Ecol. Evol. 3: 628-641.

Vanden Broeck A., Maes D., Kelager A., Wynhoff I., WallisDevries M.F., Nash D.R., Oostermeijer J.G.B., Van Dyck H. \& Mergeay J. 2017: Gene flow and effective population sizes of the butterfly Maculinea alcon in a highly fragmented, anthropogenic landscape. - Biol. Conserv. 209: 89-97.

Walters R.J., Hassel M., Telfer M.G., Hewitt G.M. \& PaluTIKOF J.P. 2006: Modelling dispersal of a temperate insect in a changing climate. - Proc. R. Soc. (B) 273: 2017-2023.

Received June 28, 2018; revised and accepted August 3, 2018 Published online August 21, 2018 